\title{
Identification of intangible assets in knowledge-based organizations using concept mapping techniques
}

\section{María del Rocío Martínez-Torres}

\author{
Departamento de Administración de Empresas y Comercialización e Investigación de Mercados \\ (Marketing), Facultad de Turismo y Finanzas, Universidad de Sevilla, Avda. San Francisco Javier, s/n \\ 41018 Sevilla, Spain. rmtorres@us.es
}

\begin{abstract}
This paper proposes a procedure for identifying the intangible assets that generate value to knowledge-intensive organizations using concept mapping techniques. Concept mapping is a form of structured conceptualization that incorporates and processes the opinion of a set of experts. A double statistical treatment consisting of a multidimensional scaling analysis and a cluster analysis is applied to a set of data provided by experts to obtain the results, which are presented in the form of maps. As a case study, the social and legal departments in a Spanish university were analyzed. As a result, 60 items referring to different intangible assets of these departments were identified and grouped into 10 clusters, and they were in turn grouped in regions corresponding to the three basic components of intellectual capital: human capital, structural capital and relational capital. The evaluation of the relative importance of each of them leads to the preeminent position of the structural capital.
\end{abstract}

\section{Introduction}

$\mathrm{N}$ owadays, intangible assets play a very important economic role in a company's well-being. This explains the interest of researchers, experts, entities and institutions to find out how to identify, measure and manage them, taking into account both the dynamic considerations and the acceptance of the intangible value at a specific moment (Roos et al., 1997; Stewart, 1997). However, not all the assets of intangible nature form part of a company's intellectual capital. For instance, reputation is the result of the use of a company's intellectual capital rather than part of it (Petty and Guthrie, 2000). According to the definition of the Organisation for Economic Co-operation and Development in 1999, intellectual capital (IC) is the economic value of two categories of intangible assets of a company: human capital (HC) and structural capital (SC). The first one refers to knowledge, skills, competences, etc. from people in an organization, while SC refers to those intangible assets that are property of the organization, such as processes, information in a database, etc. Some authors also distinguish relational capital (RC), which refers to external contacts and relations, as a separate category from SC (Petty and Guthrie, 2000, Martínez-Torres, 2006). From a resourcebased view of the firm, firm resources are the main drive behind competitiveness and firm performance, and they include both tangible physical assets as well as intangible assets.

Intellectual capital is critically important in knowledge-based organizations, where the intangible assets that generate value to an organization are more 
important than the traditional physical assets (Martínez-Torres, 2006. This is the case of universities, where their real value is not only referred to its profits or material goods, but more importantly to the knowledge of the people who work in it, the way this work is developed, or the links to other people or institutions. Therefore, the best way to measure its value is by measuring its intellectual capital.

The university, as any other organization, has its own set of relevant strategic tangible and intangible assets (Wernerfelt, 1984; Barney, 1991; Grant, 1996), which are combined to implement different strategies, and therefore to achieve its strategic goals. Although these goals are guided by a specific ministry in each country, they are also defined by the universities themselves. For instance, they have the choice to set certain priorities between research and education, or they can decide to focus on purely basic research or on applied research. As a result, universities should manage their intangible assets accordingly, including their researchers and non-scientific staff, the routines and processes, and their relationships and networks with other research institutions and companies (Leitner, 2004).

The main aim of this research consists of proposing a methodology for the identification of those intangible assets aligned with its strategic goals that generate value to the university. This research is focused on the social and legal departments of a Spanish university as a case study. The university system usually has a departmental structure (Geiger, 1990), and these departments have a direct influence over its goals. They work autonomously, although guided by the mission and goals of the university itself. Therefore, to identify the intangible assets of the university, the intangible assets of its departments should be first identified.

This paper is organized as follows. First, a brief description about intellectual capital and its relation with universities is shown. Then, the proposed methodology for the identification of intangible assets is presented. This methodology is applied to a particular case study in section 4. Reliability analysis is detailed in section 5. Finally, the major conclusions derived from this research are outlined.

\section{Intellectual capital and universities}

Intellectual capital must be assessed in order to show an effective return on investment made in the human, structural and social capital of an organization (Bontis and Fitz-enz, 2002; Wu et al., 2008). The need to assess intellectual capital is prevalent not only in private organizations but also in public organizations, such as universities and research centers (Martin, 2004). This is mainly due to the fact that universities have as main goals the production and the dissemination of knowledge. It is largely recognized by various specialists that the traditional financial and accounting systems have limitations, above all in knowledge-intensive organizations, where the value of intangible assets is much higher than tangible assets (Leitner, 2005). This is the case of universities, which are knowledge creators and disseminators, and their outcomes are measured in terms of research, publications, and enrolled and graduated students incorporating both explicit and tacit knowledge (Martínez-Torres, 2006). Besides, intellectual capital evaluation can be a source of competitiveness for universities, as a tool for reporting stakeholders their knowledge development, and as a tool for incrementing transparency and trust.

A large variety of models for evaluating intellectual capital and intangible assets have been previously reported in the literature, like the model of the intellectual capital called Magic (Warschat et al., 1999), the model for intangible analysis (Meritum Project, 2001), the model based on the business strategy (Joia, 2000), the balanced scorecard (Kaplan and Norton, 1996) or Sveiby's intangible asset monitor (Sveiby, 1997), among others. All of them have in common the starting point: the identification of the intangible assets of the organization based on its mission and its strategic goals. The reason for beginning here is because the mission is a fundamental question for the future of any organization, as well as the strategic goals to carry out this mission (Molz, 1987). Establishing some general principles is the best way for all members of the organization to know the direction to take and to concentrate their efforts. However, previous methods for measuring and reporting intangible assets are more specifically designed for private companies rather than for the public sector, and there are important differences among them (Bezhani, 2010). For instance, public sector tends to have multiple objectives of a nonfinancial nature, makes more intensive use of human resources and knowledge, and their final product is usually a service. IC reporting is even more difficult in the case of universities due to their wide range of aims and objectives that determine their performance (Leitner, 2004), and the autonomy of researchers and departments when deciding about their research strategy. HC can be clearly distinguished as the researchers and non-scientific staff of the university. However, SC includes intangibles difficult to appreciate, such as the routines and processes, and $\mathrm{RC}$ is given by the relationships and networks that can be established either by the researchers themselves or 


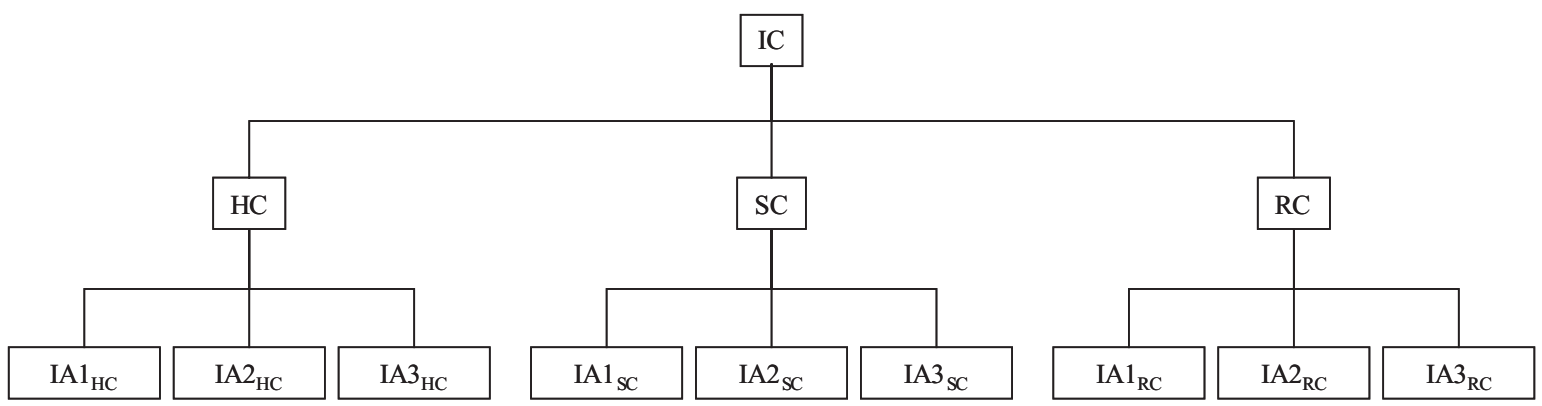

Figure 1. Components of intellectual capital. HC, human capital; IC, intellectual capital; RC, relational capital; SC, structural capital.

by the institution. Moreover, previous IC reporting methods usually identify intangibles connected with the financial dimensions. As a result, there is a need for developing new methodologies in order to identify 'new' ones (Canibano and Sanchez, 2004).

Using the mission and strategic goals as a starting point, this paper proposes a methodology based on concept mapping to determine those intangible assets that generate value in universities, following the three categories of intellectual capital. The final model to obtain is shown in Figure 1, where the three components of intellectual capital - HC, SC and RC - are defined by a series of intangibles assets.

\section{Methodology}

The process employed to identify university intangible assets is based on concept mapping techniques (Trochim, 1989a; Kolb and Shepherd, 1997). A concept map is a form of structured conceptualization that can be used by groups to develop the conceptual framework that can guide an evaluation, an exercise, a plan, etc. (Vega-Riveros et al., 1998; Toral et al., 2007). To develop the concept map, a procedure that makes use of quantitative and qualitative features was applied. First, the participants are required to generate information through brainstorming. Next, the data are structured, quantified and analyzed using a double statistical procedure that includes a multidimensional scaling and clusters analysis. Results of concept mapping show the main categories of mathematically determined ideas derived from the participants' input. Each subset of ideas is represented on the map in cluster form. Clusters closest to each other are said to be more directly linked. In summary, the maps represent the opinion of the participants.

The procedure to develop the concept map is laid out in the following steps (Kolb and Shepherd, 1997):

1. Selection and preparation of the participants. A conceptualization is better when the process includes a wide range of expert people. A broad heterogeneous participation helps ensure that the different points of view will be considered (Delbecq et al., 1975), and this will encourage 'to construct' the right conceptual framework.

2. Obtaining brainstorming items (concepts) that deal with the topic matter.

3. Structuring those items. Participants are required to classify items into homogeneous groups and to rate them. The classification from each participant generates a binary individual similarity matrix $S$ of $n x n$ dimension, $\mathrm{n}$ being the number of items. In this matrix, a value of 1 in the $(i, j)$ position means that the $i^{\text {th }}$ and $j^{\text {th }}$ items have been grouped together, and 0 otherwise. The total similarity matrix $T$ of $n x n$ dimension is obtained, adding all the individual similarity matrices. The rating matrix represents the contribution of each item to the topic under discussion.

4. Representing those items on a concept map. A double statistical treatment, consisting of a multidimensional scaling analysis and a cluster analysis, is applied to the collected data in the form of matrices. The multidimensional scaling is a technique that provides the distances between the matrix's original items. In concept mapping, this multidimensional scaling leads to a twodimensional point map that represents the set of declarations (intangible assets) made during the brainstorming session. The reason for two dimensions is that it is easier to interpret the results when they are displayed on a map. The cluster analysis organizes the information in homogeneous groups of concepts. These groups arise from the point set of the multidimensional scaling. Ward's algorithm is used since it offers more sensitive solutions and can be better interpreted than other estimates (Trochim, 1993). At first, the cluster analysis considers each item as its own cluster, thus obtaining a solution of $\mathrm{N}$ clusters, in our case 60 , corresponding to the number 
of identified intangible assets. For each level of analysis, Ward's algorithm combines two clusters until finally all the items are combined into just one cluster. It is very important to determine the number of clusters to be used in the final solution. In general, the analyst is responsible for choosing the final number of clusters so that the statements integrating each cluster conform a homogeneous meaning. As a general rule, it is preferred to err by excess than by defect, and it is preferable to have a high number of clusters than grouping heterogeneous concepts inside only one cluster (Martínez-Torres et al., 2011a).

5. Interpreting the maps.

As concept maps are usually intended for exploratory analysis where prior knowledge is scarce, an agglomerative hierarchical algorithm is chosen to perform the cluster map (Trochim, 1989a; Katsanos et al., 2008). The algorithm consists of the following steps:

- Select the finest partition

- Compute the distance matrix $D$.

DO

- Find those two clusters with the closest distance

- Merge together those two clusters

- Compute a distance between the new resulting groups obtaining a reduced distance matrix $D$.

UNTIL all clusters are agglomerated into X

Whenever two object, A and B, are united, the distance between this new group $\mathrm{A}+\mathrm{B}$ and group $\mathrm{S}$ should be evaluated using the following distance function:

$$
\begin{aligned}
d(S, A+B)= & \delta_{1} d(S, A)+\delta_{2} d(S, B)+\delta_{3} d(A, B) \\
& +\delta_{4}|d(S, A)-d(S, B)|
\end{aligned}
$$

where $\delta_{j}$ 's are weighting factors that depend on the particular chosen agglomerative algorithm. In the case of Ward algorithm, they are defined as follows:

$$
\begin{aligned}
& \delta_{1}=\frac{n_{S}+n_{A}}{n_{S}+n_{A}+n_{B}}, \delta_{2}=\frac{n_{S}+n_{B}}{n_{S}+n_{A}+n_{B}}, \\
& \delta_{3}=\frac{n_{S}}{n_{S}+n_{A}+n_{B}}, \delta_{4}=0
\end{aligned}
$$

where $\quad n_{A}=\sum_{i=1}^{n} I\left(x_{i} \in A\right), \quad n_{B}=\sum_{i=1}^{n} I\left(x_{i} \in B\right)$, $n_{S}=\sum_{i=1}^{n} I\left(x_{i} \in S\right)$ are the number of objects in group $\mathrm{A}, \mathrm{B}$ and $\mathrm{S}$, respectively.

Unlike other agglomerative techniques, Ward's method joins together the two groups that minimize the error sum of squares (i.e. the within-cluster sum of squares). It produces spherical-shaped clusters of similar sizes with a high degree of uniformity. This is exactly one of the aims of this technique: to avoid a drastic increment in a particular cluster, obtaining groups as homogeneous as possible.

The inertia inside a group is used as a measure of heterogeneity. The inertia of a group $\mathrm{S}$ is defined as follows:

$$
I_{S}=\frac{1}{n_{S}} \sum_{i=1}^{n_{S}} d^{2}\left(x_{i}, \bar{x}_{S}\right)
$$

$\bar{x}_{s}$ being the center of gravity over the groups. IS represents a measurement of the dispersion of the group around its center of gravity. Using Euclidean distance, $I_{S}$ is obtained as the sum of the variances of the $p$ components of $\mathrm{x}_{\mathrm{i}}$ inside group $\mathrm{S}$.

Whenever two objects $\mathrm{A}$ and $\mathrm{B}$ are joined together, a larger inertia value $I_{A+B}$ of the new group $A+B$ is obtained. The increment of the inertia value is given by equation (3).

$$
\Delta(A, B)=\frac{n_{A} n_{B}}{n_{A}+n_{B}} d^{2}(A, B)
$$

Those groups with the smallest increase in $\Delta(A, B)$ are merged together. In summary, Ward algorithm is similar to the centroid algorithm, but using an inertial distance instead of a geometric distance.

\section{Results}

Spain is one of the European countries that signed the Bologna Magna Charta Universitatum of 1998 to create the European Higher Education System. The Magna Charta (Bologna, 1999) states that 'the mission of the University is the transfer of knowledge and culture; the contribution of the development of society on a training level as well as on a research or cultural level; that is to say, the diffusion, appreciation and transfer of knowledge to culture, quality of life and economic development'. Spanish universities, like many other universities around the world, have a departmental structure. Therefore, we could extrapolate university goals to departments.

The first step of the proposed methodology consists of the selection of participants. This study is focused on those assets belonging to social and legal education area. In the case of the University of Seville, there are 18 departments belonging to this area. A representative from each department was invited to participate. Research and teaching expertise was required for participants. In fact, most of them (14) also have management skills as they were 


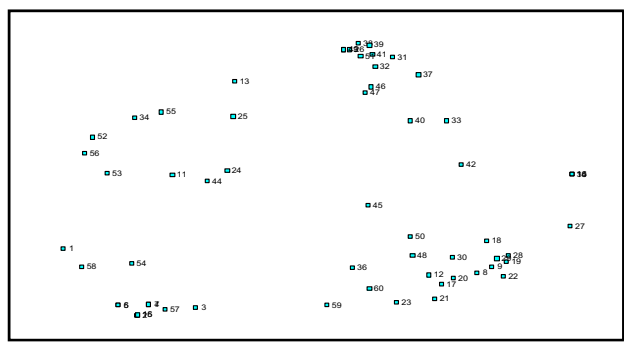

(a) Point map

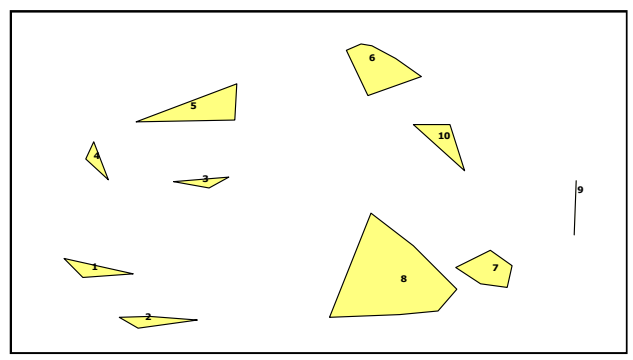

(c) Cluster map

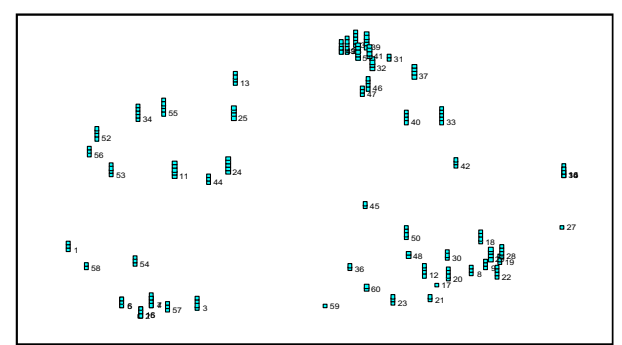

(b) Rated point map

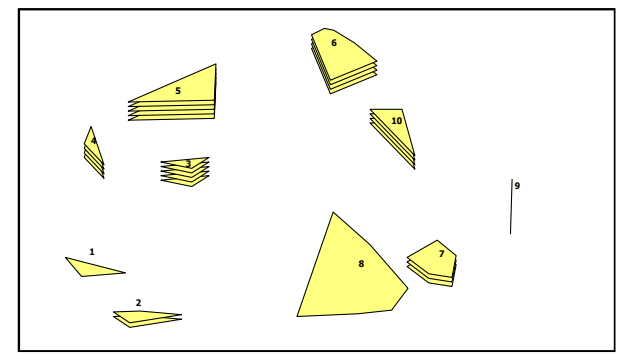

(d) Rated cluster map

Figure 2. Point and clusters map obtained from concept mapping.

the head of departments. In general, all of them have more than 20 years of experience at the university, and they are either research groups' coordinators or research projects' coordinators. Sixteen people from 16 different departments participated. This covered almost $90 \%$ of the total number of departments. This number of people is within the adequate limits for concept mapping, between 10 and 20 (Kolb and Shepherd, 1997).

Using the brainstorming technique, the 16 participants were asked to '[i]dentify those intangible assets that belong to a department and which are associated with obtaining the strategic goals of the University'. The identified statements were discussed in order to clarify their meaning and to define if they were really relevant to obtaining the strategic goals. The final list of identified intangible assets was made up of 60 items (see Appendix A).

A form with the 60 identified items was designed for structuring and rating them. The form was divided into two parts: the first one for grouping each statement into homogeneous groups, while the second one was for rating them in a 5-point rating scale, according to the contribution of each statement to the achievement of the strategic goals of the university. It was considered $1=$ 'little contribution', $5=$ 'a lot of contribution', with the numbers in between for intermediate contributions. A 'zero contribution' value was not possible since the brainstorming session specifically asked for those statements that contributed to obtaining the university's strategic goals. Therefore, all the intangible assets had some contribution. This form was filled in by the same previous work group.

The double statistical treatment provides the results in the form of maps. Figure 2 (a) shows the point map and Figure 2 (b) shows the rated point map, including the ratings provided by participants. In this case, the multilayered squares refer to the mean rating of the identified statements. The final selection of clusters is guided by the analyst, which must consider the homogeneity of the final groups. Some additional criterion, like the Elbow criterion, can be used as a first approach. Basically, the Elbow criterion compares the sum of squared differences for different cluster solutions, Figure 3. It can be appreciated a first elbow for three clusters. However, a deeper analysis considering the homogeneity of groups lead to the final 10 clusters selection (see Appendix A), illustrated in Figure 2 (c) and (d) (cluster map and rated cluster map, respectively).

The obtained maps must be interpreted by the work group by reaching a consensus in their meaning and their names. The key point is to maintain the integrity of the multidimensional scaling results; that is to say, to achieve a solution that will not allow the clusters to overlap (Martínez-Torres et al., 2011b). Seven out of 10 clusters experienced a nomenclature modification, as represented in Table 1.

- Cluster 1 'Image': It represents the image of the department, that is, the degree to which the department is known by the same or other universities, in 
business environments, in international institutions, etc.

- Cluster 2 'Contacts and Relationships': It represents the relationships and agreements taken by the members of the department with other people, institutions, universities, etc.

- Cluster 3 'Research Management': It represents how research is managed in the department, that is, the main research lines, adaptation of its research lines to national or international priorities in these particular topics, the internal and external collaboration among research groups (coordinating their activities if they belong to the same research group), participation in research calls, etc.

- Cluster 4 'Research: Application and Diffusion': It represents the degree to which the research done in a department is made known to the society, and the related impact and application of this research to the society and the environment.

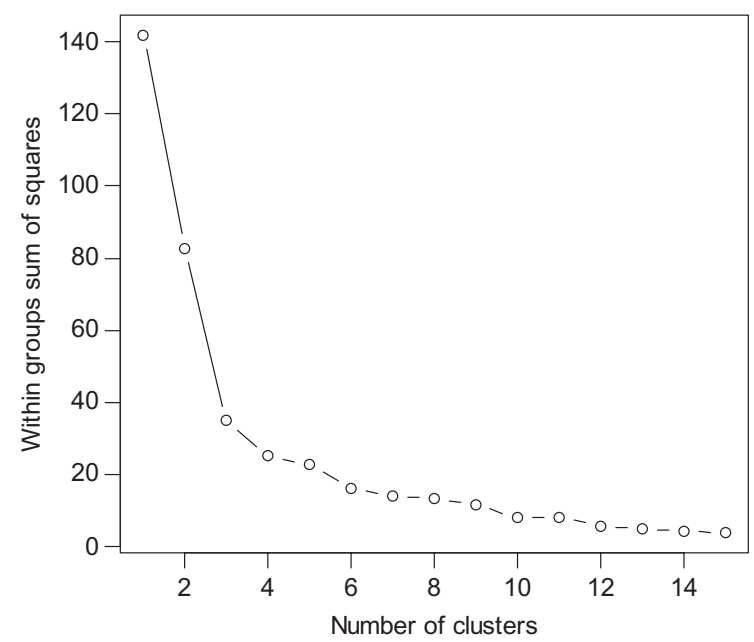

Figure 3. Elbow criterion.
- Cluster 5 'Researching Skills': It represents the skills of the members of the department related to research.

- Cluster 6 'Teaching Skills': It is related to the skills of the members of the department to teach.

- Cluster 7 'Internal Collaboration': It represents the extent to which the members of the department support themselves in teaching, research, etc.

- Cluster 8 'Organizational Management': It is related to the organizational culture for achieving the best qualification of teaching and research staff, for improving the best practices and efforts, etc.

- Cluster 9 'Personal Relationships': It represents the relationships between the members or the department.

- Cluster 10 'Teaching Improvement': It represents how the members of the department are supported by the managers of the department to improve their teaching skills.

The obtained clusters can be in turn grouped in regions or areas. On the one hand, it would be possible to identify four large areas, each one related to important activities in any department. These regions refer to education (clusters 6 and 10), research (clusters 3, 4 and 5), external relationships (clusters 1 and 2), and department (clusters 7, 8 and 9).

On the other hand, the clusters can be also grouped into three regions, according to the components of the intellectual capital, Figure 4. The first one consists of clusters related to HC (clusters 5, 6 and 9), regarding the abilities, skills, etc., of the people who belong to the organization. The second one includes clusters that can be identified as part of SC, regarding how the organization is structured (clusters 3 and 10) and how it functions (clusters 7 and 8). The last one consists of clusters related to RC (clusters 1, 2 and 4).

Table 1. Names of clusters

\begin{tabular}{lll}
\hline & Proposed name & Final name \\
\hline Cluster 1 & Image & Image \\
Cluster 2 & Contacts and relationships with environment factors & Contacts and relationships \\
Cluster 3 & Research: Internal aspects & Research management \\
Cluster 4 & Research: External aspects & Research: Application and diffusion \\
Cluster 5 & Researching skills & Researching skills \\
Cluster 6 & Teaching skills & Teaching skills \\
Cluster 7 & Rules of acting & Internal collaboration \\
Cluster 8 & Internal management and acting & Organizational management \\
Cluster 9 & Personal relationships & Personal relationships \\
Cluster 10 & Teaching management & Teaching improvement \\
\hline
\end{tabular}




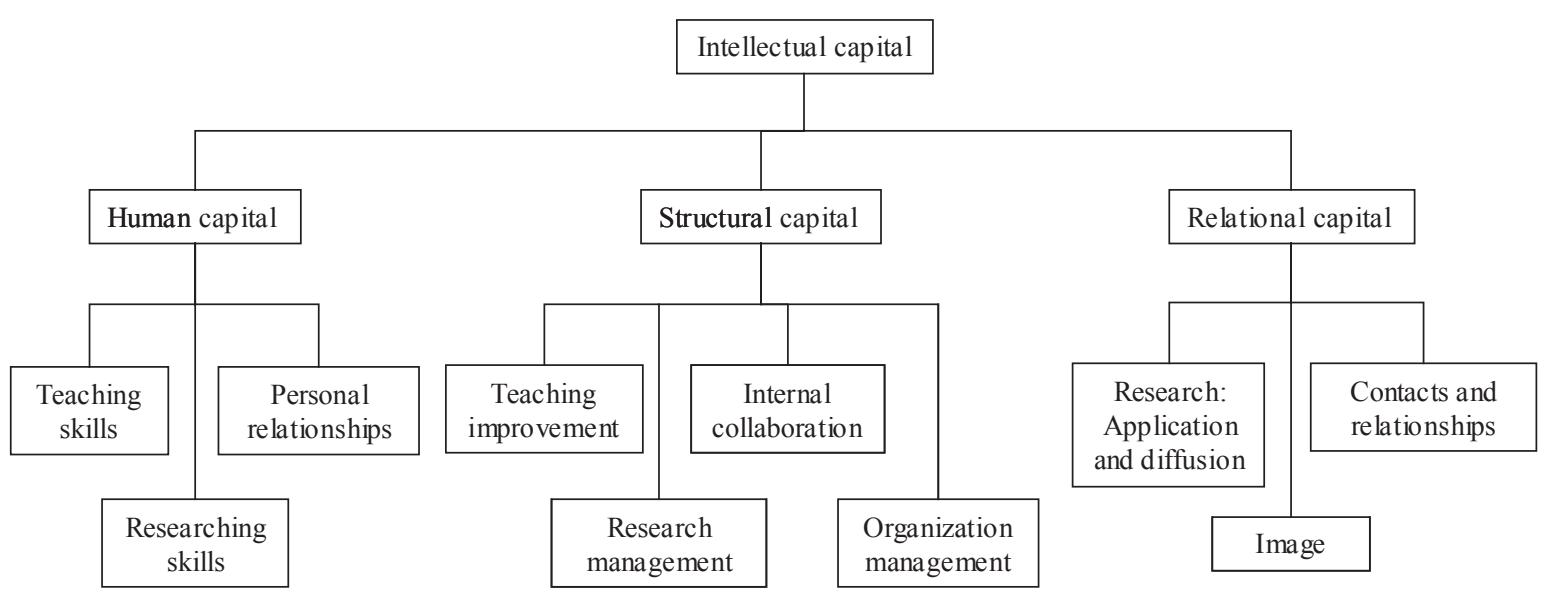

Figure 4. Intellectual capital components in a social legal university department.

Table 2. Average score of each of the intellectual capital components

\begin{tabular}{lll}
\hline $\begin{array}{l}\text { Intellectual capital } \\
\text { components }\end{array}$ & $\begin{array}{l}\text { Sum of } \\
\text { scores }\end{array}$ & $\begin{array}{l}\text { Average } \\
(\%)\end{array}$ \\
\hline Human capital & 10 & 28.57 \\
Structural capital & 16 & 45.71 \\
Relational capital & 9 & 25.71 \\
\hline
\end{tabular}

Source: Carried out by author.

Besides, it is also possible to determine which of the three components is most important according to the opinion of the experts group. This importance can be obtained from the scores of the clusters model, based on the idea that intellectual capital components are additive (Edvinsson and Malone, 1997). This is shown in Table 2.

It can be seen that two of the intellectual capital components at the university are relatively equal, but the special importance of SC is noticeable, which stems from the following clusters: research management, organizational management, internal collaboration and teaching improvement. This special importance put on SC could be due to the fact that this component is where the people's knowledge, skills and abilities 'materialize' (Tseng and James Goo, 2005). In general, organizations are interested in having a high SC, as it refers to the set of intangible assets that belong to the company. This result concurs with evidence shown by Stewart (1997) and Edvinsson and Malone (1997), who state that SC is the most important part of intellectual capital because it belongs to the company and it serves as the vehicle to convert the personal knowledge of the employees into something of value.

\section{Reliability analysis}

In most of social science studies, measurement quality is valued by reliability and validity estimation. The traditional theory about the reliability that is normally applied to social science research does not fit correctly on concept maps, as it assumes that for each item test there is a correct answer that is known in advance, and therefore the result of each individual is measured for the question and marked as either correct or incorrect. Later, the reliability for each (test of) item(s) or for the total score is estimated. However, with concept maps, one answer is not assumed to be correct or incorrect. To measure their reliability, the data matrix structure is inverted (with respect to traditional theory), so the persons are placed in columns and the items (or pairs of items) are placed in rows. The value of reliability is focused on consistency via the group of supposedly homogeneous participants. In that respect, it is helpful to talk about the reliability of the similarity matrix or the reliability of the map, but not of the reliability of individual statements (Trochim, 1993).

The key product of the concept mapping process is the two-dimensional map itself, and consequently the efforts made to verify the reliability are directed toward the central phases of analysis, development and representation.

The reliability of concept mapping was tested using six coefficients that could be easily estimated from the available data on any concept map project (Trochim, 1989b, 1993). These coefficients were obtained for a wide range of example projects, and their statistical descriptives are shown in Table 3. The statistical values can be used as a reference for analyzing the reliability of a given concept map (Trochim et al., 2006). A high level of reliability was 
Table 3. Descriptive statistics for reliability estimates for 38 concept mapping projects

\begin{tabular}{lcccccr}
\hline & $\mathrm{r}_{\text {II }}$ & $\mathrm{r}_{\mathrm{IT}}$ & $\mathrm{r}_{\mathrm{IM}}$ & $\mathrm{r}_{\mathrm{RR}}$ & $\mathrm{r}_{\mathrm{SHT}}$ & $\mathrm{r}_{\mathrm{SHM}}$ \\
\hline Number of projects & 33 & 33 & 33 & 37 & 33 & 33 \\
Mean & 0.81507 & 0.92965 & 0.86371 & 0.78374 & 0.83330 & 0.55172 \\
Median & 0.82060 & 0.93070 & 0.86280 & 0.82120 & 0.84888 & 0.55881 \\
Minimum & 0.67040 & 0.88230 & 0.74030 & 0.42700 & 0.72493 & 0.25948 \\
Maximum & 0.93400 & 0.97370 & 0.95490 & 0.93540 & 0.93269 & 0.90722 \\
SD & 0.07016 & 0.02207 & 0.04771 & 0.12125 & 0.05485 & 0.15579 \\
Our map & 0.87283 & 0.95697 & 0.93506 & 0.82941 & 0.80534 & 0.77223 \\
\hline
\end{tabular}

Source: Trochim (1993) and carried out by author.

found within our case study. Furthermore, the indicators were found to be valid and within the standards shown by Trochim.

Individual-to-individual sort reliability $\left(\mathrm{r}_{\mathrm{II}}\right)$ correlates each person's binary sort matrix, $\mathrm{S}_{\mathrm{nxn}}$, for each pair of individuals; that is to say, it deals with how the sorts are correlated for the different participants in the development of the concept map. This is identified by calculating the average of these correlations and by applying the Spearman-Brown prophecy formula (Nunnally, 1978).

$$
r_{k k}=\frac{k \overline{r_{i j}}}{1+(k-1) \overline{r_{i j}}}
$$

That is,

- $\mathrm{r}_{\mathrm{ij}}=$ correlation estimated from the data

- $\mathrm{k}=\mathrm{N} / \mathrm{n}$, where $N$ is the total sample size and $n$ is the sample size on which $r_{i j}$ is based

- $\mathrm{r}_{\mathrm{kk}}=$ reliability estimated according to the Spearmen Brown Prophecy formula.

Individual-to-total matrix reliability $\left(\mathrm{r}_{\mathrm{IT}}\right)$ correlates each person's binary sort matrix $S_{n x n}$, with the total matrix $\mathrm{T}_{\mathrm{nxn}}$; that is to say; it deals with determining how the sorts carried out by each person correlate with all the sorts. To find the calculation, we must take the average of these correlations and apply the Spearmen-Brown Prophecy formula.

Individual-to-map reliability $\left(\mathrm{r}_{\mathrm{IM}}\right)$ correlates each person's binary sort matrix, $S_{\mathrm{nxn}}$, with the Euclidean matrix distances, $\mathrm{D}_{\mathrm{nxn}}$. To find this calculation, we take the average of these correlations and apply the Spearmen-Brown prophecy formula.

Average inter-sort reliability $\left(\mathrm{r}_{\mathrm{RR}}\right)$ calculates the correlation among the scores of each pair of persons. In order to find the calculation, we take the average of these correlations and apply the Spearmen-Brown prophecy formula.

Split-half reliabilities ( $\mathrm{r}_{\mathrm{SHT}}$ and $\mathrm{r}_{\mathrm{SHM}}$ ) divides the set of sorts from each project into two halves and calcu- lates concept maps for each group. The total matrices, $\mathrm{T}_{\mathrm{A}}$ y $\mathrm{T}_{\mathrm{B}}$, are correlated and then the SpearmenBrown Prophecy formula is applied in order to obtain $\mathrm{r}_{\mathrm{SHT}}$. The Euclidean distances were correlated between all pairs of points on the two maps, $\mathrm{D}_{\mathrm{A}} \mathrm{y} \mathrm{D}_{\mathrm{B}}$, and the Spearmen-Brown correction was applied in order to achieve $\mathrm{r}_{\mathrm{SH}}$.

In short, we can say that our concept map is reliable since the different reliability indicators showed values within the acceptable limits set by Trochim.

\section{Conclusions and implications}

Taking intangible assets lists from previous literature has always been done to study the intellectual capital in the university. However, the main problem of this solution is that the list of intangible assets is based on the personal experience of the authors or in generic assets. As an alternative, in this research, we have identified the intangible assets that make up intellectual capital in a university department through a scientific technique: the concept mapping technique. IC reporting as conceptualized here focuses on the identification of intangible assets and tries to link them to the goals of the universities. The intangible assets identified through this technique are compatible with the literature on intellectual capital since its different components (HC, SC and RC) can be easily identified in the obtained map.

The relative importance of each one of the intellectual capital components has also been proven, reaching the conclusion that $\mathrm{SC}$ is the most prominent. This result concurs with the claims of some authors, who state that this component is the most important for the organization and refer to the intangible assets that belong to the company (Edvinsson and Malone, 1997; Tseng and James Goo, 2005).

Universities usually do not need to produce the kind of annual reports required by commercial law. However, as they are typically financed by public 
funding, they are required by the owners and citizens for transparency regarding the use of those funds. Therefore, new management and reporting systems within universities are required. In this context, IC reporting can fulfill this gap by providing information for the management of intangible resources and information for external stakeholders about the development and productive use of the intellectual capital. One of the advantages of IC reporting is that it allows the comparability between different universities and enables their quality assurance. This is an important issue in the context of the harmonization of European university systems, or in the elaboration of the different international rankings of universities. The position of universities in international rankings is today considered a strategic issue for most universities (Docampo, 2011).

Additionally, IC reporting allows universities to self-organize in a more efficient way. This study highlights the special importance of managing the SC of departments, coordinating their internal efforts, and encouraging the coordination with other departments and research groups. The internationalization of the teaching and research activity is also an important issue that is included in the strategic policies of top universities.

The presented framework of intangible assets in the university is obviously a first step. It is flexible enough for individual adaptations and adjustments depending on the particular features of each university system, and has the potential for further improvement and elaboration. As a future step, specific indicators for each of the obtained intangible assets could be defined, facilitating the comparability of IC reporting. Another point that requires further investigation is the relationship among research production, performance measurements and IC reporting. Longitudinal studies about these three topics could help understand the way in which intellectual capital is promoting the general goals of universities. The main limitation of the study is that it is restricted to a particular case in a Spanish university.

\section{References}

Barney, J. (1991) Firm resources and sustained competitive advantage. Journal of Management, 17, 99-120.

Bezhani, I. (2010) Intellectual capital reporting at UK universities. Journal of Intellectual Capital, 11, 2, 179-207.

Bontis, N. and Fitz-enz, J. (2002) Intellectual capital ROI: a causal map of human capital antecedents and consequents. Journal of Intellectual Capital, 3, 3, 223-247.

Canibano, L. and Sanchez, M.P. (2004) Measurement, management and reporting on intangibles: state-of-the- art. Readings on Intangibles and Intellectual Capital, AECA, Madrid, pp. 81-113.

Delbecq, A.L., van de Ven, A.H., and Gustafson, D.H. (1975) Group Techniques for Program Planning: A Guide to Nominal Group and Delphi Processes. Glenview, IL: Scott Foresman.

Docampo, D. (2011) On using the Shanghai ranking to assess the research performance of university systems. Scientometrics, 86, 1, 77-92.

Edvinsson, L. and Malone, M.S. (1997) Intellectual Capital: Realizing Your Company's True Value by Finding Its Hidden Brainpower. New York: Harper Business.

Geiger, R.L. (1990) Organized research units - their role in the development of university research. Journal of Higher Education, 61, 1-19.

Grant, R.M. (1996) Toward a knowledge-based theory of the firm. Strategic Management Journal, 17, 109-122.

Joia, L.A. (2000) Measuring intangible corporate assets. Linking business strategy with intellectual capital. Journal of Intellectual Capital, 1, 1, 68-84.

Kaplan, R.S. and Norton, D.P. (1996) The Balanced Scorecard: Translating Strategy into Action. Boston, MA: Harvard Business School.

Katsanos, C., Tselios, N., and Avouris, N. (2008) Automated semantic elaboration of web site information architecture. Interacting with Computers, 20, 6, 535-544.

Kolb, D.G. and Shepherd, D.M. (1997) Concept mapping organizational cultures. Journal of Management Inquiry, 6, 4, 282-295.

Leitner, K.-H. (2004) Intellectual capital reporting for universities: conceptual background and application for Austrian universities. Research Evaluation, 13, 2, 129 140 .

Leitner, K.-H. (2005) Managing and reporting intangible assets in research technology organisations. $R \& D$ Management, 35, 2, 125-136.

Martin, W.J. (2004) Demonstrating knowledge value: a broader perspective on metrics. Journal $f$ Intellectual Capital, 5, 1, 77-91.

Martínez-Torres, M.R. (2006) A procedure to design a structural and measurement model of intellectual capital: an exploratory study. Information \& Management, 43, 5, 617-626.

Martínez-Torres, M.R., Toral, S.L., and Barrero, F. (2011a) Identification of the design variables of eLearning tool. Interacting with Computers, 23, 3, 279-288.

Martínez-Torres, M.R., Díaz-Fernández, M.C., Toral, S.L., and Barrero, F.J. (2011b) Identification of new added value services on intelligent transportation systems. Behaviour \& Information Technology, 32, 3, 307-320.

Meritum Project. (2001) Guidelines for managing and reporting on intangibles, Intellectual Capital Report.

Molz, R. (1987) How leaders use goals. Long Range Planning, 20, 5, 91-101.

Nunnally, J.C. (1978) Psychometric Theory, 2nd edn. New York: McGraw Hill.

Petty, R. and Guthrie, J. (2000) Intellectual capital literature review measurement, reporting and management. Journal of Intellectual Capital, 1, 2, 155-176. 
Roos, J., Roos, G., Dragonetti, N.C., and Edvinsson, L. (1997) Intellectual Capital: Navigating in the New Business Landscape. Houndmills, Basingstoke: Macmillan.

Stewart, T.A. (1997) Intellectual Capital: The New Wealth of Organizations. New York: Doubleday/Currency.

Sveiby, K.E. (1997) The intangible asset monitor. Journal of Human Resource Costing and Accounting, 2, 1, 73-97.

Toral, S.L., Martínez-Torres, M.R., Barrero, F.J., Gallardo, S., and Durán, M.J. (2007) An electronic engineering curriculum design based on concept-mapping techniques. International Journal of Technology and Design Education, 17, 3, 341-356.

Trochim, W. (1989b) Concept mapping: soft science or hard art? Evaluation and Program Planning, 12, 1, 87-110.

Trochim, W., Cabrera, D.A., Milstein, B., Gallagher, R.S., and Leischow, S.J. (2006) Practical challenges of systems thinking and modeling in public health. American Journal of Public Health, 96, 3, 538-546.

Trochim, W.M.K. (1989a) An introduction to concept mapping for planning and evaluation. Evaluation and Program Planning, 12, 1, 1-16.

Trochim, W.M.K. (1993) The reliability of concept mapping. Annual Conference of the American Evaluation Association, Dallas, Texas, November 6.

Tseng, C.-Y. and James Goo, Y.-J. (2005) Intellectual capital and corporate value in an emerging economy: empirical study of Taiwanese manufacturers. $R \& D$ Management, 35, 2, 187-201.

Vega-Riveros, J.F., Marciales-Vivas, G.P., and MartínezMelo, M. (1998) Concept maps in engineering education: a case study. Global Journal of Engineering Education, 2, 1, 21-27.

Warschat, J., Wagner, K., and y Haub, I. (1999) Measurement system for the evaluation of R\&D knowledge in the engineering sector, Information Society Technologies. Intellectual Capital/Intangible Investments, November 22, 1999. Report on workshop at the IST Conference 1999, Helsinki.

Wernerfelt, B. (1984) A resource based view of the firm. Strategic Management Journal, 5, 2, 171-180.

Wu, W.-Y., Chang, M.-L., and Chen, C.-W. (2008) Promoting innovation through the accumulation of intellectual capital, social capital, and entrepreneurial orientation. $R \& D$ Management, 38, 3, 265-277.

María del Rocío Martínez-Torres was born in Madrid, Spain, in 1973. She received an MSc degree in business administration and a $\mathrm{PhD}$ degree in business administration, both from the University of Seville, Spain, in 1996 and 2003, respectively. She is currently an associate professor in the Department of Business Administration, US. Her research interests include intellectual capital, open source software projects, virtual communities of practice, evaluation of utility and use of e-learning tools, and knowledge management.

\section{Appendix A. Clusters}

\section{Cluster 1: Image}

1. The image of the department is good.

54. The department do marketing to make it known to others.

58. The image of the University which the department belongs to is good.

\section{Cluster 2: Contacts and relationships}

2. There are people in the department which belongs to the University Management Structure.

3. In the department there is a scientific and prestigious professor.

4. There are people in the department with good contacts and relationships.

5. There are relationships between people from the department and public institutions.

6. There are relationships between people from the department and private institutions.

7. There are relationships between people from the department and editorials boards.

15. There are relationships between people from the department and other universities.

16. There are links/relationships between people from the department and other university departments.

57. People in the department has competence to looking for new projects with firms.

\section{Cluster 3: Research management}

11. In the department the researching groups are operative.

24. Teaching and research are encouraged in the department.

44. Research results are made known to everybody in the department.

\section{Cluster 4: Research: Application and diffusion}

52. There is applied research in the department.

53. The research results are disseminated outside the department.

56. Research is close to society demands.

\section{Cluster 5: Researching skills}

13. The members in the department have research and teaching experience. 
25. There is a link between research and teaching in the department.

34. The research in the department is of high quality. 55. People with research responsibilities have skills for research.

\section{Cluster 6: Teaching skills}

26. In the department the teaching contents are updated.

31. There is only one programme-schedule for each subject.

32. The evaluation system is appropriate for the subject explained.

37. Professors in the department have communicative skills.

38. Professors have enough knowledge of the subject they explain.

39. Professors have teaching skills.

41. Professors innovate in their teaching.

43. Relationships among Professors and students are good.

46. In the department, study and training is encouraged.

47. The reference material is good for the subjects to be explained.

49. There are relationships with students.

51. The teaching in the department is of a high quality.

\section{Cluster 7: Internal collaboration}

8. There is an internal system to control the quality in the department.

9. There are internal meetings in the department. 18. The skills and human capacities are well managed in the department.

19. There is internal cohesion in the department.

22. There are internal communication processes.

28. Decision-making is done by consensus.
29. The 'rules of the game' are known by everybody and they are stable in time.

\section{Cluster 8: Organizational management}

12. Initiatives are encourage in the department.

17. Managers in the department change.

20. The organizative structure of the department is good.

21. In the department the administrative activities are done within the specified period.

23. There is a network which links everybody in the department.

30. The materials resources are well managed.

45. The department has study grants for good students.

48. People who evaluate entrance tests change.

50. Access to information is easy.

36. Prestigious Associate professors from private firms are recruited.

59. The department is placed in a good place.

60. Managers in the department have management skills to manage extra-departmental activities.

\section{Cluster 9: Personal relationship}

10. The relationships among colleagues are good. 14. There are people of high human quality in the department.

27. There is a meeting place in the department.

35. There are good informal relationships among colleagues in the department.

\section{Cluster 10: Teaching improvement}

33. Professors dedicate enough time to preparing their lectures.

40. Professors training is encouraged in the department.

42. The people in the department have skills for learning. 